\title{
B-cell lymphomas involving Waldeyer's ring characterized by distinctive clinical and histopathological features: a comparison of pediatric to adult patients
}

\author{
Lei Chen ${ }^{1}$, Lika'a Fasih Y. Al-Kzayer ${ }^{2}$, Yi Liu', Tingting Liu ${ }^{3}$ \\ ${ }^{1}$ Department of Pathology, Xinhua Hospital, Shanghai Jiaotong University School of Medicine, Shanghai, China \\ ${ }^{2}$ Department of Pediatrics, Shinshu University School of Medicine, Matsumoto, Nagano, Japan \\ ${ }^{3}$ Department of Pediatric Hematology/Oncology, Xinhua Hospital, Shanghai Jiaotong University School of Medicine, Shanghai, \\ China
}

Correspondence to: Tingting Liu, email: tingtingliu16@yahoo.co.uk

Keywords: $B$-cell lymphoma, Waldeyer's ring, MUM1 positive lymphoma

Received: April 06, $2016 \quad$ Accepted: December 16, $2016 \quad$ Published: January 10, 2017

\section{ABSTRACT}

B-cell lymphomas involving Waldeyer's ring (WR) comprise heterogeneous histolopathological subtypes with a wide age range and distinctive clinical features. However, the comparison between pediatric and adult patients is scarce and limited in the literature. Thirty-three cases of B-cell lymphomas involving WR, were collected and evaluated by histolopathological, immunohistochemical and FISH analyses. The 33 cases were categorized into children and adolescents referred as pediatric group $(n=12)$, aged $(3-19)$ years and the adult group $(n=21)$, aged $(20-84)$ years. The pediatric group included Burkitt lymphoma (BL), diffuse large B-cell lymphoma (DLBCL) and MUM1-positive-lymphoma in 7, 3 and 2 cases, respectively. While the adult cases comprised of DLBCL, follicular lymphoma, and mucosa associated lymphoid tissue (MALT) lymphoma in 18, 2 and 1 case, respectively. Male gender was predominant in both groups with 3 folds frequency in the pediatric cases compared to 2 folds in the adults counterpart. Pediatric cases showed a significantly higher frequency of stage I disease $(P=0.019)$, germinal center B-cell (GCB) phenotype $(P=0.011), C D 10$-positive expression $(P=0.003)$, and MYC breaks $(P=0.029)$ compared to adults. However, MUM1 positive expression was less frequently detected in pediatric patients than adults $(P=0.082)$. BCL2 rearrangement was undetectable in both pediatric and adult groups. On the other hand, adult group had the significantly higher proportion of DLBCL $(P<0.001)$, BCL2 expression $(P=0.027)$ and stage II disease $(P=0.047)$ compared to pediatric group.

In conclusion, B-cell lymphomas involving WR presented with a wide age range, and evident variation in clinical features, histopathological subtypes and immunophenotypes between pediatric and adult age groups.

\section{INTRODUCTION}

B-cell lymphomas involving Waldeyer's ring (WR) comprise heterogeneous histolopathological subtypes with a wide age range and distinctive clinical features. WR is composed of lymphoid tissue of the nasopharynx and oropharynx, including the adenoids (pharyngeal tonsil), the lymphoid tissue around the pharyngeal openings of the Eustachian tubes (tubal tonsils), the palatine tonsils, lymphoid tissue of the soft palate and base of the tongue (lingual tonsil) [1]. WR represents one of the most common extra nodal sites for lymphoma development [2]. The most common subtypes of Non-Hodgkin's lymphoma (NHL) involving WR, in children and adults, are Burkitt lymphoma (BL) and diffuse large B-cell lymphoma (DLBCL), respectively. Follicular lymphoma (FL) involving WR also occurs in both children and adults. Of note, DLBCL involving WR displays peculiar clinicopathological features compared to nodal counterpart [3]. Patients with a GCB subtype of DLBCL were shown to have a significantly better clinical outcome than those with the non-GCB subtype [4]. 
Pediatric FL (PFL), occurring rarely in pediatric and young adults, differs from usual adult FL (AFL) in their clinical, morphologic, immunophenotypic and molecular features [5]. Compared to nodal PFL, PFL in WR is characterized by the co-expression of IRF4/MUM1 and BCL6, in addition to the frequent expression of BCL2 in the absence of $\mathrm{t}(14 ; 18)$, as well as the association with $I G H$ gene rearrangement and BCL6 gene alteration [6]. IRF4/MUM1positive-lymphoma in WR of children and young adults has been recently considered a new separate entity [7].

The vast majority of NHLs involving WR are of B-cell origin with a wide age range. Given the available published literatures, adult cases were described in accordance to their distinctive features and found to be of high-grade histology, early stage disease and of favorable outcome, whereas reports concerned with pediatric patients were limited [8,9]. Furthermore, comparison studies between the two age groups were scarce.

In this study, we summarized both the common and the different clinicopathological characters of pediatric and adult B-cell lymphomas involving WR. Moreover, we focused on MUM1 expression in variable histological subtypes of B-cell lymphomas involving WR in pediatrics as well as the adult patients.

\section{RESULTS}

The clinical features of 36 cases of NHL involving WR, including 33 cases of B-cell lymphoma, 2 cases of NK/T-cell lymphoma and 1 case of T-cell lymphoblastic lymphoma, were summarized in Table 1.

\section{Comparison of B-cell lymphoma between pediatric and adult groups of patients}

The 33 patients with B-cell lymphoma, with a wide age range of 3-84 years (median, 52), were arbitrary classified as shown in Figure 1, into children and adolescent group (12 cases), aged 3-19 years (median, 5.5), hereafter referred to as pediatric group, and the adult group (21 cases) aged 27-84 years (median, 57). A male predominance (M: $\mathrm{F}=23: 10$ ), was evident among the 33 patients, and the pediatric cases were 3 folds more frequent ( $\mathrm{M}: \mathrm{F}=9: 3)$, compared to 2 folds in adult cases (M: $F=14: 7)$.

Symptoms were related to the location of the mass lesion, with more frequency of pharyngalgia and/or cervical lymphadenopathy. Pediatric patients exhibited other symptoms, including rhinorrhea, obstructive sleep apnea, and epistaxis, in addition to dysphagia and snoring. Given the available information about 29 out of 33 cases regarding disease stage, a high frequency was shown for the localized disease stages I and II, with 21\% (6/29) and $55 \%(16 / 29)$ frequencies, respectively, compared to the advanced disease stage III, with a relatively lower frequency of $24 \%(7 / 29)$. Among the 12 pediatric patients, stage I, II and III were identified in 5 (42\%), 4 (33\%) and
$3(25 \%)$ cases, respectively. Compared with the group of 17 adults with the known staging, stage I, II and III, were identified in $1(6 \%), 12(70.5 \%)$ and $4(23.5 \%)$, respectively. Thus, clinical stage I, was significantly more frequent among pediatric patients $(P=0.019)$, while on the contrary, stage II was significantly more common in the adult group $(P=0.047)$.

Data of the treatment and follow-up were available for 26 cases of B-cell lymphoma, including 9 pediatric and 17 adult patients. The 26 patients received surgical excision/biopsy, followed by chemotherapy (25 patient) or local radiation (1 patient). The median follow-up period was 17 months (ranging from 3 to 38 months) (Table 1). Two cases had relapsed including, one child with BL (case 4) and one adult patient with DLBCL (case 22). Meanwhile, case number 26 had developed multiple organ failure after the first cycle of chemotherapy and died.

Immunophenotype study revealed that the 33 cases were consistently positive for B-cell markers (CD20, CD79a and PAX5) and variably positive for MUM1 and CD10 (Figure 2). As shown in Table 2, MUM1 was positive in $18 \%(2 / 11)$ pediatric cases, which were classified as MUM1-positive-lymphoma involving WR. MUM1 was also positive in 50\% (10/20) adult patients, including 4 cases of GCB-DLBCL and 6 cases of nonGCB-DLBCL. The remaining patients were negative for MUM1, providing that it was not evaluated in 2 cases. CD10 was positive in 58\% (19/33) cases, and it was significantly expressed in the pediatric group; $92 \%$ $(11 / 12)$, compared to adult group; 38\% (8/21), $(P=0.003)$. As shown in Figure $2(\mathrm{~F}-\mathrm{H}), 75 \%(24 / 32)$ of the cases presented with GCB phenotype and $25 \%$ (8/32) of cases were of non-GCB phenotype. GCB immunophenotype was the unique profile in the pediatric group; $100 \%$ $(12 / 12)$, compared with the adult cases with $60 \%(12 / 20)$, $(P=0.011)$. The proliferation index as detected by Ki-67 ranged from $50-100 \%$ (median, 80\%), except for the case of MALT lymphoma. BCL2 was positively expressed in $66 \%(21 / 32)$ cases, with a significantly higher frequency among adult patients of $80 \%(16 / 20)$, compared to the pediatric cases of $42 \%(5 / 12),(P=0.027)$. The $I G H$ $B C L 2$ rearrangement was neither detectable among the 10 pediatric cases nor the 11 adult cases with the available data, as it was not evaluated in the rest of the cases. MYC breaks were positively expressed in $27.3 \%(6 / 22)$ of our series, and were significantly more frequent among the pediatric cases; constituting half of the 10 evaluated cases and representing all the evaluated BL cases. On the other hand, $8.3 \%(1 / 12)$ adult patient of DLBCL subtype expressed MYC breaks (Figure 3).

Pathological distribution showed that the most common subtypes among the 33 cases of B-cell lymphomas were DLBCL; 64\% (21/33), followed by BL; $21 \%$ (7/33), FL; 12\% (4/33), and MALT lymphoma; 3\% (1/33). The 12 pediatric cases comprised of BL, PDLBCL and PFL in 7, 3 and 2 cases, respectively, while 21 adult 
Table 1: Clinical features of 36 cases with non-Hodgkin's lymphoma involving Waldeyer's ring

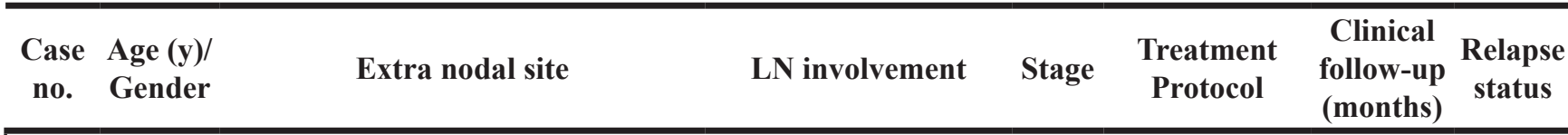

\begin{tabular}{|c|c|c|c|}
\hline \multicolumn{4}{|c|}{ B-cell lymphoma } \\
\hline \multicolumn{4}{|c|}{ 1-BL } \\
\hline 1 & $3 / \mathrm{M}$ & Nasopharynx and pancreatic gland & Cervical LN \\
\hline 2 & $3 / \mathrm{M}$ & Rt. palatine tonsil & Cervical LN \\
\hline 3 & $4 / \mathrm{M}$ & Nasopharynx, lung and T11 vertebrae & Cervical LN \\
\hline 4 & $4 / F$ & $\begin{array}{l}\text { Rt. palatine tonsil and Rt. parotid } \\
\text { gland }\end{array}$ & $\begin{array}{l}\text { Cervical, axillary, and } \\
\text { inguinal LN }\end{array}$ \\
\hline 5 & $4 / \mathrm{F}$ & Rt. palatine tonsil & No involvement \\
\hline 6 & $6 / \mathrm{M}$ & Nasopharynx and Rt. palatine tonsil & Cervical LN \\
\hline 7 & $6 / \mathrm{M}$ & Lt. palatine tonsil & Cervical LN \\
\hline
\end{tabular}

2-DLBCL

\begin{tabular}{|c|c|c|c|c|c|c|c|}
\hline \multicolumn{8}{|c|}{ PDLBCL } \\
\hline 8 & $5 / \mathrm{M}$ & Rt. palatine tonsil & Cervical LN & II & NA & NA & NA \\
\hline 9 & $8 / \mathrm{M}$ & Lt. palatine tonsil & No involvement & $\mathrm{I}$ & CCCG-BNHL & 19 & No \\
\hline 10 & $19 / \mathrm{F}$ & Rt. palatine tonsil & No involvement & I & CCCG-BNHL & 38 & No \\
\hline \multicolumn{8}{|c|}{ ADLBCL } \\
\hline 11 & $27 / \mathrm{M}$ & Lt. palatine tonsil & NA & NA & $\mathrm{NA}$ & $\mathrm{NA}$ & $\mathrm{NA}$ \\
\hline 12 & $42 / \mathrm{M}$ & Nasopharynx & NA & NA & NA & NA & NA \\
\hline 13 & $47 / \mathrm{F}$ & \begin{tabular}{|lll}
$\begin{array}{l}\text { Bilateral palatine tonsil and } \\
\text { nasopharynx }\end{array}$ & & \\
\end{tabular} & $\begin{array}{l}\text { Cervical and abdominal } \\
\text { LN }\end{array}$ & III & R-CHOP & 14 & No \\
\hline 14 & $48 / \mathrm{F}$ & Oropharynx, stomach, and spleen & $\begin{array}{l}\text { Cervical and abdominal } \\
\text { LN }\end{array}$ & III & $\begin{array}{l}\text { R-CHOP+ } \\
\text { R-EPOCH }\end{array}$ & 13 & No \\
\hline 15 & $53 / \mathrm{M}$ & Lt. palatine tonsil & NA & NA & NA & NA & NA \\
\hline $16 *$ & $54 / \mathrm{M}$ & Tonsil & Cervical LN & II & R-EPOCH & 4 & No \\
\hline 17 & $56 / \mathrm{M}$ & Rt. palatine tonsil & NA & NA & R-CHOP & 18 & No \\
\hline 18 & $57 / \mathrm{M}$ & Lt. palatine tonsil & Cervical LN & II & $\begin{array}{l}\text { R-CHOP+ } \\
\text { R-EPOCH }\end{array}$ & 20 & No \\
\hline 19 & $57 / \mathrm{M}$ & Nasopharynx and oropharynx & $\begin{array}{l}\text { Cervical and axillary } \\
\text { LN }\end{array}$ & II & \begin{tabular}{|l|l}
$\mathrm{R}-\mathrm{CHOP}$ \\
$+\mathrm{R}-\mathrm{EPOCH}$ \\
\end{tabular} & 10 & No \\
\hline 20 & $60 / \mathrm{M}$ & Lt. palatine tonsil & Cervical LN & II & NA & NA & NA \\
\hline 21 & $61 / \mathrm{M}$ & Lt. palatine tonsil & Cervical LN & II & R-CHOP & 21 & No \\
\hline 22 & $62 / \mathrm{F}$ & Rt. palatine tonsil & Cervical LN & II & R-CHOP & 17 & Yes \\
\hline 23 & $64 / F$ & Nasopharynx & $\begin{array}{l}\text { Cervical, axillary, and } \\
\text { inguinal LN }\end{array}$ & III & R-CHOP & 16 & No \\
\hline 24 & $68 / \mathrm{M}$ & Rt. palatine tonsil and hypothyroid & Cervical LN & II & R-CHOP & 32 & No \\
\hline $25 *$ & $72 / \mathrm{M}$ & Rt. palatine tonsil & $\begin{array}{l}\text { Cervical and inguinal } \\
\text { LN }\end{array}$ & III & R-CHOP & 8 & No \\
\hline 26 & $84 / \mathrm{M}$ & Lt. palatine tonsil and parotid & $\begin{array}{l}\text { Cervical and axillary } \\
\text { LN }\end{array}$ & II & R-CHOP & 6 & No** \\
\hline 27 & $52 / \mathrm{M}$ & Lt. palatine tonsil & Cervical LN & II & R-CHOP & 19 & No \\
\hline 28 & $54 / \mathrm{F}$ & Oropharynx & Cervical LN & II & R-CHOP & 3 & No \\
\hline \multicolumn{8}{|c|}{ 3- Follicular lymphoma } \\
\hline \multicolumn{8}{|c|}{ PFL (MUM1 positive lymphoma) * } \\
\hline 29 & $11 / \mathrm{M}$ & Nasopharynx and Lt. palatine tonsil & No involvement & $\mathrm{I}$ & CCCG-BNHL & 26 & No \\
\hline 30 & $7 / \mathrm{M}$ & Rt. palatine tonsil & No involvement & I & CCCG-BNHL & 22 & No \\
\hline \multicolumn{8}{|c|}{ AFL / FL 3B } \\
\hline 31 & $64 / \mathrm{F}$ & Lt. palatine tonsil & Cervical LN & II & R-CHOP & 17 & No \\
\hline 32 & $60 / \mathrm{F}$ & Rt. palatine tonsil & Cervical LN & II & R-EPOCH & 20 & No \\
\hline
\end{tabular}




\begin{tabular}{|c|c|c|c|c|c|c|c|}
\hline \multicolumn{8}{|c|}{ 4-MALT lymphoma } \\
\hline 33 & $58 / \mathrm{M}$ & Oropharynx & No involvement & I & Radiation & 8 & No \\
\hline \multicolumn{8}{|c|}{ T-cell lymphoma } \\
\hline \multicolumn{8}{|c|}{ NK/T-cell lymphoma } \\
\hline 34 & $47 / \mathrm{F}$ & Nasopharynx & No involvement & I & & NA & NA \\
\hline 35 & $44 / \mathrm{M}$ & Nasal cavity and nasopharynx & Cervical LN & II & & 12 & Yes** \\
\hline \multicolumn{8}{|c|}{ T-Lymphoblastic lymphoma } \\
\hline 36 & $3 / \mathrm{M}$ & Nasopharynx & Cervical LN & II & & 19 & No \\
\hline
\end{tabular}

* In accordance to new classification "large B-cell lymphomas with IRF4 rearrangement"; ** Cases died from progressive diseases.

ADLBCL, adult diffuse large B-cell lymphoma; AFL, adult follicular lymphoma; BL, Burkitt lymphoma; DLBCL, diffuse large B-cell lymphoma; F, female; FL, follicular lymphoma; LN, lymph node; Lt., left; M, male; MALT, mucosa associated lymphoid tissue; NA, not available; PDLBCL, pediatric DLBCL; PFL, pediatric follicular lymphoma; R-CHOP, (R, Rituximab; CHOP, cyclophosphamide, adriamycin, vincristine, prednisone); R-EPOCH regimen (R, Rituximab; EPOCH, etoposide, prednisone, vincristine, cyclophosphamide, and adriamycin); Rt., right.

cases were composed of ADLBCL, AFL, and MALT lymphoma in 18, 2 and 1 case, respectively (Table 3). DLBCL was of significant higher proportion among adult cases compared to the pediatric group $(P<0.001)$, whereas $\mathrm{BL}$ subtype was exclusively related to pediatric group.

\section{Different histopathological subtypes of B-cell lymphoma involving WR}

Regarding $\mathrm{BL}$, the age range was 3-6 years (median, 4) and (M: F = 5:2), included 14\% (1/7) with stage I, $43 \%(3 / 7)$ with stage II, and $43 \%(3 / 7)$ with stage III. BL showed positive expression of CD10 in all the 7 cases, and BCL6 in $83 \%(5 / 6)$, whereas negative expression for both MUM1 and BCL2. As shown in Figure 2 (E), nearly $100 \%$ of the neoplastic cells were positive for Ki-67.

Comparing PDLBCL to ADLBCL, the 21 patients with DLBCL and DLBCL/FL ranged from 5-84 years old (median, 54) and a gender ratio of (M: $\mathrm{F}=15: 6)$, including PDLBCL patients aged 5-19 years (median, 8) with (M: $\mathrm{F}=2: 1$ ), and 18 ADLBCL patients with an age range of 27-84 years (median, 56) with (M: $\mathrm{F}=13: 5)$. As shown in Table 1, PDLBCL exhibited an earlier clinical process

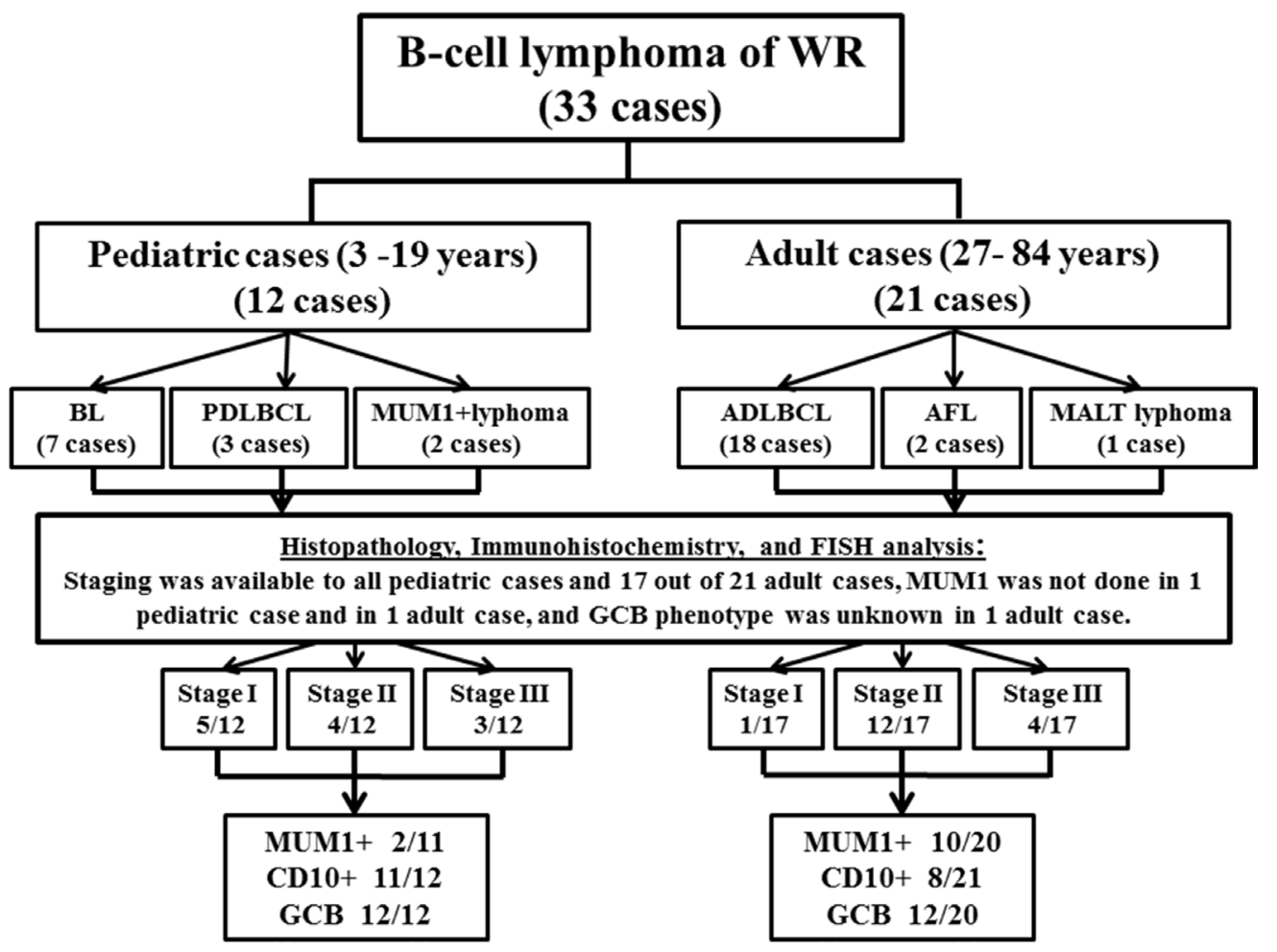

Figure 1: The description of the categorization of 33 cases of B-cell lymphoma of WR. 

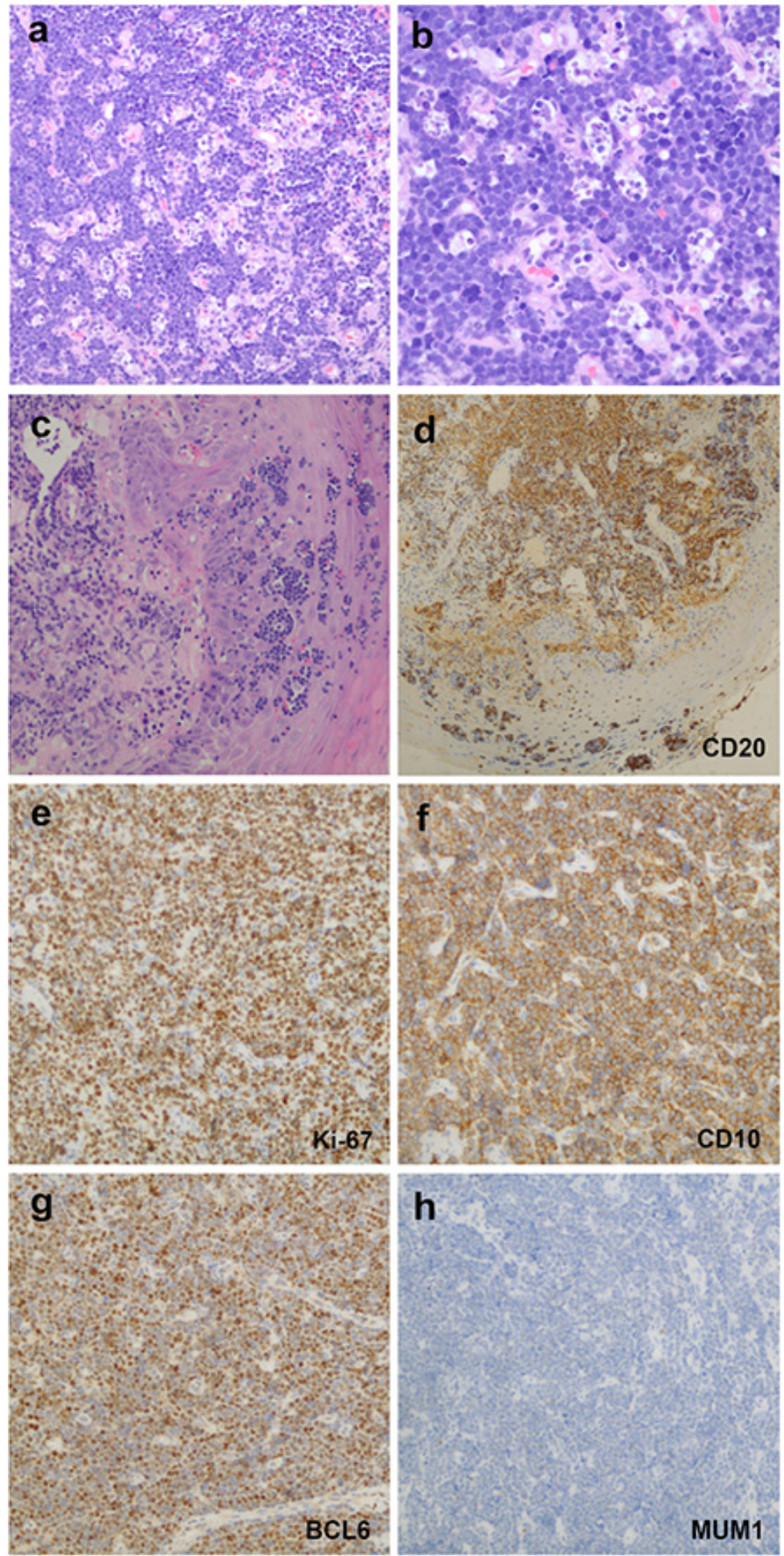

Figure 2: Histopathological and immunohistochemical characteristics of B-cell lymphomas involving WR. (A, B), Case 1, BLs showed morphological features with a prominent starry-sky growth pattern at low magnification (A) Hematoxylin and eosin, HE, original magnification $\times 200$ ) and a population of monomorphous medium-sized cells with round to slightly irregular nuclei, finely clumped chromatin and multiple small nucleoli at high magnification (B) HE, original magnification $\times 400)$. $(\mathbf{C}-\mathbf{H})$ Case 17, DLBCLs revealed that the neoplastic cells infiltrated the epithelium (Hematoxylin and eosin, HE, original magnification $\times 200$ ). (D) Lymphoepithelial lesions showed positive expression for $\mathrm{CD} 20$ staining (HE, original magnification $\times 400$ ). e, Ki-67 proliferation index was over $90 \%$ of neoplastic cells staining. The GCB subtype case showed positive expression of CD10 (F) and BCL6 (G) but a negative expression of MUM1 (H). Samples were stained for indicating target antigen by IHC; HE, original magnification $\times 200$. 
Table 2: Immunophenotypic characteristics of 33 cases with B-cell lymphoma involving Waldeyer's ring

\begin{tabular}{|c|c|c|c|c|c|c|c|c|}
\hline \multirow{2}{*}{ Case no. } & \multicolumn{6}{|c|}{ IHC } & \multicolumn{2}{|c|}{ FISH } \\
\hline & CD10 & BCL6 & MUM1 & Ki-67 & BCL2 & MYC & IGH/BCL2 & MYC \\
\hline \multicolumn{9}{|l|}{ 1-BL } \\
\hline 1 & + & + & - & $95 \%+$ & - & + & - & + \\
\hline 2 & + & + & - & $90 \%+$ & - & + & - & + \\
\hline 3 & + & + & - & $100 \%+$ & - & + & - & + \\
\hline 4 & + & + & - & $95 \%+$ & - & + & - & + \\
\hline 5 & + & ND & ND & $95 \%+$ & - & ND & ND & ND \\
\hline 6 & + & - & - & $100 \%+$ & - & + & - & + \\
\hline 7 & + & + & - & $95 \%+$ & - & ND & ND & ND \\
\hline \multicolumn{9}{|l|}{ 2-DLBCL } \\
\hline \multicolumn{9}{|l|}{ PDLBCL } \\
\hline 8 & - & + & - & $60 \%+$ & + & - & - & - \\
\hline 9 & + & + & - & $80 \%+$ & + & - & - & - \\
\hline 10 & + & + & - & $90 \%+$ & + & - & - & - \\
\hline \multicolumn{9}{|l|}{ ADLBCL } \\
\hline 11 & + & + & - & $80 \%+$ & + & ND & - & - \\
\hline 12 & - & + & + & $80 \%+$ & + & - & ND & $\mathrm{ND}$ \\
\hline 13 & $\begin{array}{lll}- & \\
\end{array}$ & + & $\begin{array}{ll}- \\
-\end{array}$ & $70 \%+$ & + & + & $\begin{array}{lll}- & \\
\end{array}$ & - \\
\hline 14 & - & - & + & $90 \%+$ & + & ND & - & - \\
\hline 15 & - & - & - & $70 \%+$ & - & ND & ND & ND \\
\hline 17 & - & + & + & $90 \%+$ & + & ND & - & + \\
\hline $16^{*}$ & + & + & + & $90 \%+$ & - & - & ND & - \\
\hline 18 & - & + & + & $70 \%+$ & + & ND & - & - \\
\hline 19 & + & + & - & $70 \%+$ & + & ND & ND & ND \\
\hline 20 & - & ND & ND & $90 \%+$ & ND & ND & ND & ND \\
\hline 21 & - & + & + & $70 \%+$ & + & ND & - & - \\
\hline 22 & - & + & - & $70 \%+$ & + & ND & ND & $\mathrm{ND}$ \\
\hline 23 & - & + & - & $80 \%+$ & + & - & - & - \\
\hline 24 & - & + & - & $70 \%+$ & + & ND & ND & ND \\
\hline $25^{*}$ & + & + & + & $80 \%+$ & + & - & ND & $\mathrm{ND}$ \\
\hline 26 & + & - & + & $60 \%+$ & + & ND & ND & ND \\
\hline 27 & + & - & + & $95 \%+$ & - & - & - & - \\
\hline 28 & - & + & + & $80 \%+$ & + & - & - & - \\
\hline \multicolumn{9}{|c|}{ 3- Follicular lymphoma } \\
\hline \multicolumn{9}{|c|}{ PFL (MUM1 positive lymphoma) } \\
\hline 29 & + & + & + & $70 \%+$ & + & - & - & - \\
\hline 30 & + & + & + & $50 \%+$ & + & - & - & - \\
\hline \multicolumn{9}{|c|}{ AFL / FL 3B } \\
\hline 31 & + & + & - & $50 \%+$ & + & ND & - & - \\
\hline 32 & + & + & - & $95 \%+$ & - & - & - & - \\
\hline \multicolumn{9}{|c|}{ 4-MALT lymphoma } \\
\hline 33 & - & - & - & $10 \%+$ & + & ND & ND & ND \\
\hline
\end{tabular}

*In accordance to new classification "large B-cell lymphomas with IRF4 rearrangement".

ADLBCL, adult diffuse large B-cell lymphoma; AFL, adult follicular lymphoma; BL, Burkitt lymphoma; DLBCL, diffuse large B-cell lymphoma; FL, follicular lymphoma; FISH, fluorescence in situ hybridization; IHC, immunohistochemistry; MALT, mucosa associated lymphoid tissue; ND, not done; PDLBCL, pediatric DLBCL; PFL, pediatric follicular lymphoma. 
compared to ADLBCL. The 3 cases of PDLBCL presented with stage I in 2 cases and with stage II in 1 patient, and all of them were of GCB phenotype. On the other hand, adult cases with available data of clinical stage were presented with stage II and III, in 71\% (10/14) and 29\% (4/14) cases, respectively. Evaluation of the ADLBCL cases with the known phenotype disclosed that 53\% (9/17) were of GCB, and $47 \%(8 / 17)$ were of the non-GCB phenotype.

Comparing PFL to AFL, 4 cases of FL included 2 pediatric cases of 7 and 11-year-old boys (both with stage I and MUM1-positive-FL) and 2 adult patients of 60 and 64-yearold women (both with stage II and MUM1-negative-FL).

One case of MALT lymphoma was diagnosed in a 58-year-old man who presented with stage I disease, with negative CD10, MUM1 and BCL2, suggesting the nonGCB phenotype. In addition, in the latter case, Ki-67 was positive in $10 \%$ of the neoplastic cells.

\section{DISCUSSION}

NHLs involving WR are associated with heterogeneous histological distribution occurring in both pediatric and adult patients. Most of the NHLs involving WR were of B-cell origin with distinctive biological and clinical behavior. However, the relationship among clinical features, pathological subtypes and age groups was unclear.
In the current study, 33 of 36 NHL cases were of B-cell lymphoma type, and the subtypes varied among pediatric and adult patients. The most common subtype in children was BL, followed by DLBCL and FL whereas DLBCL was predominantly found in adults, followed by FL.

Histological subtype was the most influencing factor for the clinical significance in patients with lymphomas. BL in children and MALT lymphoma in adults generally represented more favorable outcomes than DLBCL. Therefore, the different distribution and morbidity of histological subtypes would be the main contributor for different clinical presentation between pediatric and adult patients. Age was relatively important to affect the clinical outcome for the same histological subtype of lymphoma. Compared to ADLBCL, as shown in our results, PDLBCL exhibited earlier clinical stages and a higher rate of GCB phenotype, with better prognosis.

As previously described, NHL involving WR demonstrated a more favorable outcome for the localized stage disease compared to the nodal counterpart [3]. Similarly, in our series of cases, most of B-cell lymphomas involving WR presented with stage I/II disease and a significantly higher incidence of stage I among pediatric age group compared to adults. Furthermore, despite the relatively high rate of $43 \%(3 / 7)$ of the advanced clinical stage, the prognosis of BL involving WR in our cases, was
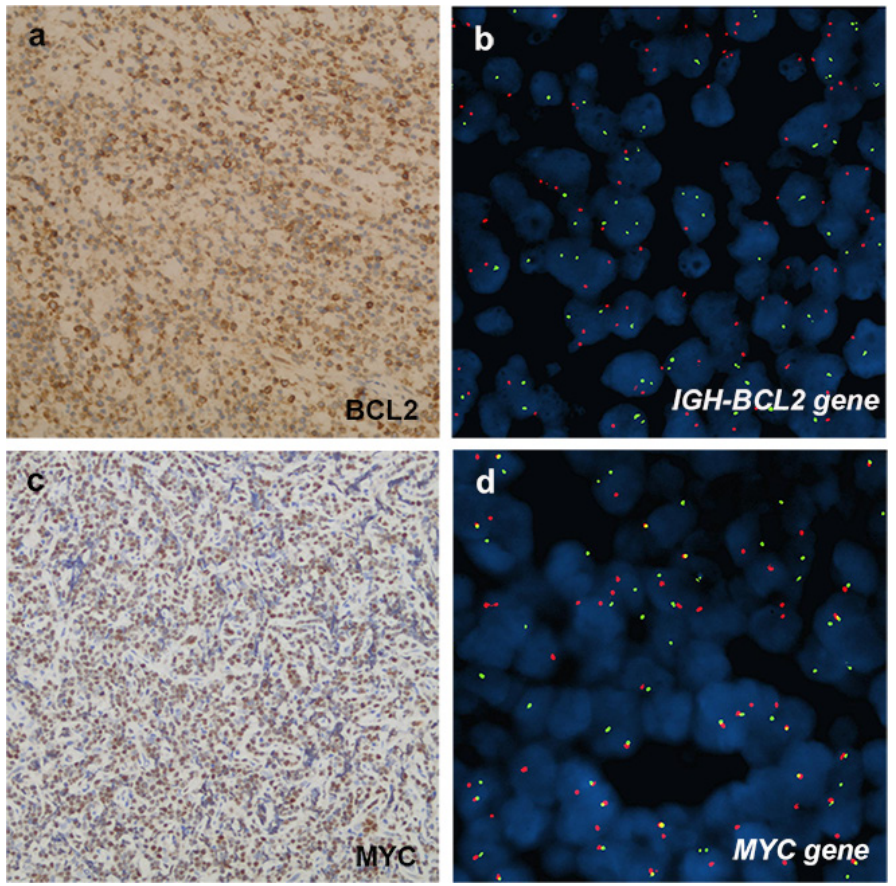

Figure 3: Immunohistochemical and cytogenetic features of B-cell lymphomas involving WR. (A, B), case 8, PDLBCL. (A) BCL2 was positively expressed in neoplastic cells. b, FISH analysis did not detect a positive fusion signal in BCL2 of the samples. LSI $I G H / B C L 2$ dual-color, dual-fusion probe signal pattern expected for $\mathrm{t}(14 ; 18)(\mathrm{q} 32 ; \mathrm{q} 21)$. SpectrumOrange-labeled BCL2 probe and SpectrumGreen-labeled IGH probe correspond to 18q21 and 14q32, respectively. (C, D), case 3, BL. (C) MYC was positive expression. (D) Presence of LSIMYC Dual Color, BreakApart Rearrangement Probe signal pattern with abnormal nucleus showing a one orange, one green and one orange/green fusion signal pattern. Normal probe hybridizes to the band region 8q24. SpectrumOrange probe begins upstream of the $5^{\prime}$ end of MYC and SpectrumGreen probe starts downstream of 3' of the MYC gene. 
Table 3: Comparison of children and adolescent cases (pediatric group) and adult cases (adult group) with high grade B-cell lymphomas involving Waldeyer's ring

\begin{tabular}{|c|c|c|c|}
\hline Variable & $\begin{array}{l}\text { Group } 1 \text { (3-19 years) } \\
n=12 \\
\text { no. }(\%)\end{array}$ & $\begin{array}{l}\text { Group } 2(20-84 \text { years }) \\
n=21 \\
\text { no. }(\%)\end{array}$ & $P$-value \\
\hline \multicolumn{4}{|l|}{ Clinical features } \\
\hline Median age, year (range) & $5.5(3-19)$ & $57(27-84)$ & \\
\hline M: F & $9: 3$ & $14: 7$ & 0.616 \\
\hline \multicolumn{4}{|l|}{ Clinical stage } \\
\hline Stage I & $5 / 12(42)$ & $1 / 17(6)$ & 0.019 \\
\hline Stage II & $4 / 12(33)$ & $12 / 17(71)$ & 0.047 \\
\hline Stage III & $3 / 12(25)$ & $4 / 17(24)$ & 0.927 \\
\hline \multicolumn{4}{|l|}{\begin{tabular}{|l|} 
Histologic classification \\
\end{tabular}} \\
\hline $\mathrm{BL}$ & $7 / 12(58)$ & $0 / 21(0)$ & \\
\hline DLBCL & $3 / 12(25)$ & $18 / 21(86)$ & $<0.001$ \\
\hline FL & $2 / 12(17)$ & $2 / 21(9)$ & 0.545 \\
\hline MALT lymphoma & $0 / 12(0)$ & $1 / 21(5)$ & \\
\hline \multicolumn{4}{|l|}{ Immunohistochemical features } \\
\hline GCB & $12 / 12(100)$ & $12 / 20(60)$ & 0.011 \\
\hline CD10+ & $11 / 12(92)$ & $8 / 21(38)$ & 0.003 \\
\hline MUM1+ & 2/11 (18) & $10 / 20(50)$ & 0.082 \\
\hline BCL2+ & $5 / 12(42)$ & $16 / 20(80)$ & 0.027 \\
\hline \multicolumn{4}{|l|}{ Genetic features } \\
\hline$I G H / B C L 2$ & $0 / 10(0)$ & $0 / 11(0)$ & \\
\hline MYC breaks & $5 / 10(50)$ & $1 / 12(8)$ & 0.029 \\
\hline \multicolumn{4}{|l|}{\begin{tabular}{|l|} 
Outcome \\
\end{tabular}} \\
\hline Relapse & $1 / 9(11)$ & $1 / 17(12)$ & 0.634 \\
\hline
\end{tabular}

BL, Burkitt lymphoma; DLBCL, diffuse large B-cell lymphoma; F, female; FL, follicular lymphoma; GCB, germinal center B-cell; M, male; MALT, mucosa associated lymphoid tissue.

associated with favorable outcome and low incidence of recurrence $14 \%(1 / 7)$.

Ki-67 index was closely related to the histopathological subtypes which were different in pediatric and adult patients. Despite of nearly $100 \%$ positive expression of Ki-67, BL in children showed a sensitive therapeutic effect and good prognosis. Hence, the relativity of Ki-67 expression and the prognostic value were not correlated in the different subtypes and age groups. In the current report, 32 of 33 cases of B-cell lymphomas were of high grade B-cell lymphomas with a Ki-67 of high proliferation index ranging from $50-100 \%$. Of note, higher proliferation index of at least $80 \%$ was associated with poor outcome in adult series $[10,11]$. On the other hand, Miles et al, reported that pediatric DLBCL was frequently associated with high histological grade and high proliferation index, however, showed a superior prognosis compared to adults [12]. Similarly, in our pediatric BL series, despite of nearly $100 \%$ positive expression of Ki- 67 , the response was good.

The GCB phenotype was reported to occur in 50-60\% of adult DLBCL and was associated with a better prognosis compared to those with non-GCB phenotype $[13,14]$. Comparable to previous report concerned with PDLBCL, which showed a higher proportion of GCB subtype and a more superior prognosis as compared with adult disease, our data disclosed that $75 \%$ of the B-cell lymphoma cases involving WR were of GCB phenotype, representing all the pediatric cases, and $60 \%$ of adult cases phenotype [12]. MUM1 represented the most important non-GCB marker, and the clinical meaning of MUM1 and CD10 mainly related to the histological subtypes of lymphomas.

Although BCL2 was positive in $66 \%$ of cases, no $I G H / B C L 2$ rearrangement was detectable in this study, in accordance with previous studies which showed low rates of BCL2 translocations of DLBCLs involving WR [3]. Taken together, BCL2 protein expression was reported to be associated with poor prognosis, however, recent studies suggested that the prognostic value of BCL2 expression is restricted to non-GCB tumor only [15].

MYC rearrangement was identified in 100\% (5/5) BL cases and $8 \%(1 / 13)$ case of DLBCL, whereas no $B C L 2$ rearrangement was detectable in our series. $M Y C$ rearrangement was related to poor prognosis in DLBCL and $\mathrm{FL}$, but not in BL. Thus, $B C L 2$ and $M Y C$ rearrangements affect the disease prognosis differently in accordance to the histological subtypes of lymphoma. Moreover, 
MYC/BCL2 protein co-expression contributes to the inferior survival of non-GCB subtype of DLBCL [16]. Therefore, the low co-expression of BCL2/MYC in our series of cases could explain our observation of the favorable prognosis of B-cell lymphomas involving WR.

As reported recently, IRF4 translocation was identified as a primary molecular alteration in a subset of GCB-derived lymphomas. The probability for this subtype of lymphoma significantly decreases with age, suggesting that diversity in tumor biology might contribute to the agedependent differences in the prognosis of lymphoma [17].

Recent studies highlighted the significance of MUM1 expression in PFL involving WR. Meanwhile, compared to its nodal counterpart, PFL involving WR was thought to be a distinctive subtype of PFL, characterized by the uniform positivity for MUM1 [6]. Though, the incidence of MUM1 expression in both the PDLBCL and the AFL involving WR, had not yet been described.

Our two patients (cases 29 and 30) were initially diagnosed after surgery as PFL grade 3B with MUM1positive-lymphoma in WR. However, with the updated understanding of WR, these cases would best fit the new entity classification of large B-cell lymphomas with IRF4 rearrangement [18]. In contrast, MUM1 expression, was not detectable in other subtypes of our cases of pediatric B-cell lymphoma involving WR, including BL and PDLBCL. Therefore, MUM1-positive expression was the "hall mark" of immunoreaction for PFL involving WR, which might be helpful for distinguishing this newly recognized entity from other pediatric lymphomas. A previously reported paper disclosed that some cases of MUM1positive-lymphoma expressed CD5 protein as well [6]. Interestingly, one of our patients (case 30) was strongly and diffusely positive for CD5, therefore, we reported the child's clinicopathological presentation in details [19].

\section{MATERIALS AND METHODS}

Our study was approved by the Ethics Committee of Xinhua Hospital Affiliated to Shanghai Jiaotong University School of Medicine. All cases were obtained from the files of a single institution. This study was based on a retrospective review of 443 cases previously diagnosed as lymphoma within the period from September 2012 to January 2016. Among the total of 443, 36 cases of lymphomas involving WR were identified according to histological and immunohistochemical analyses, in reference to 2008 World Health Organization classification. Ann Arbor classification was used for staging. Clinical information was recorded for each patient including age, gender, date of initial diagnosis, symptoms and signs at presentation, clinical and/or pathological stage, in addition to treatment information. Patient's survival status and follow-up time were assessed as well.
Nine pediatric patients received chemotherapy in accordance to the China Children's Cancer Group (CCCG)-BNHL protocol. On the other hand, the protocols used for adults included either R-CHOP (rituximab, cyclophosphamide, adriamycin, vincristine, and prednisone), or R-EPOCH (rituximab, etoposide, prednisone, vincristine, cyclophosphamide, and adriamycin), or both R-CHOP and $\mathrm{R}-\mathrm{EPOCH}$ regimens were used in 10, 3, and 3 patients, respectively. The patient with MALT lymphoma received radiation only. Written informed consent was previously obtained from each patient and/or guardians in accordance to the guidelines of the Declaration of Helsinki.

\section{Histologic and immunohistochemistry analyses}

Formalin-fixed, paraffin-embedded tissue samples were available for all the 36 cases and were stained with hematoxylin and eosin (HE) at initial diagnosis. Immunohistochemistry was performed using a panel of monoclonal and polyclonal antibodies, as follows: CD20 (clone L26, DAKO, Glostrup, Denmark); CD79a (clone 1.10E+04, Leica Biosystems, Wetzlar, Germany); PAX5 (clone R1, DAKO); CD10 (clone 56C6, Leica Biosystems); BCL6 (clone P1F6, DAKO); MUM1 (clone MUM1p, DAKO); Ki-67 (clone MIB-1, DAKO); BCL2 (clone 100/D5, DAKO); MYC (DAKO); EBV (DAKO); terminal deoxynucleotidyl transferase (TDT, clone SP150, DAKO); CD3 (clone LN10, Leica Biosystems); CD43 (clone DF-T1, DAKO). MYC was considered as positive when $>40 \%$ of tumor cells exhibited staining [20]. Positivity threshold was defined at $50 \%$ for BCL2 [20], and at 30\% for CD10, BCL6, and MUM1 [4]. For subclassification of DLBCLs, GC immunophenotype was evaluated by antibodies of C10, BCL6 and MUM1 [4].

\section{FISH analyses}

FISH was performed on 3-4 $\mu \mathrm{m}$ thick sections of formalin-fixed paraffin-embedded tissue samples, employing BCL2 (LSI IGH/BCL2 dual-color dual-fusion probe, Vysis-Abbott, IL, USA), and MYC (LSIMYC Dual Color, BreakApart Rearrangement Probe, Vysis-Abbott, IL, USA) to detect $\mathrm{t}(14 ; 18)(\mathrm{q} 32 ; \mathrm{q} 21)(I G H / B C L 2)$ and $M Y C$ gene rearrangement, respectively. The cut-off values for the interphase FISH analyses were established following the criteria of Ventura et al, and for each sample 100 evaluable nuclei with complete FISH signals were scored [21].

\section{Statistical analysis}

Contingency tables were analyzed using Pearson chi-square statistic. Differences with $P$-value $<0.05$ were defined as statistical significance. The software of SPSS version 17.0 (SPSS Inc., Chicago, IL, USA) was used for statistical calculations. 


\section{CONCLUSIONS}

In conclusion, B-cell lymphomas involving WR presented with a wide age range, male predominance, high rate of the localized clinical stage, a favorable outcome despite the high-grade histopathology, high rate of GCB phenotype, and more frequency of BCL2 expression lacking $I G H / B C L 2$ rearrangement. Moreover, pediatric patients differed from adults in terms of clinical features, histopathological subtypes and immunophenotypes. Notably, MUM1 was positive in a subset of GCBADLBCL and exclusively in MUM1-positive-lymphoma/ PFL involving WR among pediatric patients.

\section{ACKNOWLEDGMENTS AND FUNDING}

None

\section{CONFLICTS OF INTEREST}

The authors declare no competing financial interests.

\section{REFERENCES}

1. Tan LH. Lymphomas involving Waldeyer's ring: placement, paradigms, peculiarities, pitfalls, patterns and postulates. Ann Acad Med Singapore. 2004; 33:15-26.

2. Laskar S, Mohindra P, Gupta S, Shet T, Muckaden MA. Non-Hodgkin lymphoma of the Waldeyer's ring: clinicopathologic and therapeutic issues. Leuk Lymphoma. 2008; 49:2263-71.

3. de Leval L, Bonnet C, Copie-Bergman C, Seidel L, Baia M, Brière J, Molina TJ, Fabiani B, Petrella T, Bosq J, Gisselbrecht C, Siebert R, Tilly H, et al. Diffuse large B-cell lymphoma of Waldeyer's ring has distinct clinicopathologic features: a GELA study. Ann Oncol. 2012; 23:3143-51.

4. Hans CP, Weisenburger DD, Greiner TC, Gascoyne RD, Delabie J, Ott G, Müller-Hermelink HK, Campo E, Braziel RM, Jaffe ES, Pan Z, Farinha P, Smith LM, et al. Confirmation of the molecular classification of diffuse large B-cell lymphoma by immunohistochemistry using a tissue microarray. Blood. 2004; 103:275-82.

5. Louissaint A Jr, Ackerman AM, Dias-Santagata D, Ferry JA, Hochberg EP, Huang MS, Iafrate AJ, Lara DO, Pinkus GS, Salaverria I, Siddiquee Z, Siebert R, Weinstein HJ, et al. Pediatric-type nodal follicular lymphoma: an indolent clonal proliferation in children and adults with high proliferation index and no BCL2 rearrangement. Blood. 2012; 120:2395-2404.

6. Liu Q, Salaverria I, Pittaluga S, Jegalian AG, Xi L, Siebert R, Raffeld M, Hewitt SM, Jaffe ES. Follicular lymphomas in children and young adults: a comparison of the pediatric variant with usual follicular lymphoma. Am J Surg Pathol. 2013; 37:333-43.

7. Quintanilla-Martinez L, Sander B, Chan JK, Xerri L, Ott G, Campo E, Swerdlow SH. Indolent lymphomas in the pediatric population: follicular lymphoma, IRF4/MUM1+ lymphoma, nodal marginal zone lymphoma and chronic lymphocytic leukemia. Virchows Arch. 2016; 468:141-57.

8. Guimarães AC, de Carvalho GM, Bento LR, Correa C, Gusmão RJ. Clinical manifestations in children with tonsillar lymphoma: A systematic review. Crit Rev Oncol Hematol. 2014; 90:146-51.

9. Lee SJ, Suh CW, Lee SI, Kim WS, Lee WS, Kim HJ, Choi CW, Kim JS, Shin HJ; Consortium for Improving Survival of Lymphoma. Clinical characteristics, pathological distribution, and prognostic factors in nonHodgkin lymphoma of Waldeyer's ring: nationwide Korean study. Korean J Intern Med. 2014; 29:352-60.

10. Broyde A, Boycov O, Strenov Y, Okon E, Shpilberg O, Bairey O. Role and prognostic significance of the Ki-67 index in non-Hodgkin's lymphoma. Am J Hematol. 2009; $84: 338-43$.

11. Miller TP, Grogan TM, Dahlberg S, Spier CM, Braziel RM, Banks PM, Foucar K, Kjeldsberg CR, Levy N, Nathwani BN, et al. Prognostic significance of the Ki67-associated proliferative antigen in aggressive nonHodgkin's lymphomas: a prospective Southwest Oncology Group trial. Blood. 1994; 83:1460-66.

12. Miles RR, Raphael M, McCarthy K, Wotherspoon A, Lones MA, Terrier-Lacombe MJ, Patte C, Gerrard M, Auperin A, Sposto R, Davenport V, Cairo MS, Perkins SL. SFOP/LMB96/CCG5961/UKCCSG/NHL 9600 Study Group. Pediatric diffuse large B-cell lymphoma demonstrates a high proliferation index, frequent c-Myc protein expression, and a high incidence of germinal center subtype: Report of the French-American-British (FAB) international study group. Pediatr Blood Cancer. 2008; 51:369-74.

13. Alizadeh AA, Eisen MB, Davis RE, Ma C, Lossos IS, Rosenwald A, Boldrick JC, Sabet H, Tran T, Yu X, Powell JI, Yang L, Marti GE, et al. Distinct types of diffuse large B-cell lymphoma identified by gene expression profiling. Nature. 2000; 403: 503-11.

14. Berglund M, Thunberg U, Amini RM, Book M, Roos G, Erlanson M, Linderoth J, Dictor M, Jerkeman M, CavallinStåhl E, Sundström C, Rehn-Eriksson S, Backlin C, et al. Evaluation of immunohpenotype in diffuse large B-cell lymphoma and its impact on prognosis. Mod Pathol. 2005; 18:1113-20.

15. Iqbal J, Neppalli VT, Wright G, Dave BJ, Horsman DE, Rosenwald A, Lynch J, Hans CP, Weisenburger DD, Greiner TC, Gascoyne RD, Campo E, Ott G, et al. BCL2 expression is a prognostic marker for the activated B-cell-like type of diffuse large B-cell lymphoma. J Clin Oncol. 2006; 24:961-68.

16. $\mathrm{Hu} \mathrm{S}, \mathrm{Xu}-$ Monette ZY, Tzankov A, Green $\mathrm{T}, \mathrm{Wu} \mathrm{L}$, Balasubramanyam A, Liu WM, Visco C, Li Y, Miranda RN, Montes-Moreno S, Dybkaer K, Chiu A, et al. MYC/ BCL2 protein coexpression contributes to the inferior survival of activated B-cell subtype of diffuse large B-cell 
lymphoma and demonstrates high-risk gene expression signatures: a report from The International DLBCL Rituximab-CHOP Consortium Program. Blood. 2013; 121:4021-31.

17. Salaverria I, Philipp C, Oschlies I, Kohler CW, Kreuz M, Szczepanowski M, Burkhardt B, Trautmann H, Gesk S, Andrusiewicz M, Berger H, Fey M, Harder L, et al. Molecular Mechanisms in Malignant Lymphomas Network Project of the Deutsche Krebshilfe; German High-Grade Lymphoma Study Group; Berlin-Frankfurt-MünsterNHL trial group. Translocations activating IRF4 identify a subtype of germinal center-derived B-cell lymphoma affecting predominantly children and young adults. Blood. 2011; 118:139-47.

18. Swerdlow SH, Campo E, Pileri SA, Harris NL, Stein H, Siebert R, Advani R, Ghielmini M, Salles GA, Zelenetz AD, Jaffe ES. The 2016 revision of the World Health Organization classification of lymphoid neoplasms. Blood. 2016; 127:2375-90. doi: 10.1182/blood-2016-01-643569.
19. Chen L, Al-Kzayer LF, Liu T, Kobayashi N, Nakazawa Y, Koike K. IFR4/MUM1-positive lymphoma in Waldeyer ring with co-expression of CD5 and CD10. Pediatr Blood Cancer. 2017; 64:311-314.

20. Johnson NA, Slack GW, Savage KJ, Connors JM, BenNeriah S, Rogic S, Scott DW, Tan KL, Steidl C, Sehn LH, Chan WC, Iqbal J, Meyer PN, et al. Concurrent expression of MYC and BCL2 in diffuse large B-cell lymphoma treated with rituximab plus cyclophosphamide, doxorubicin, vincristine, and prednisone. J Clin Oncol. 2013; 30:3452-59.

21. Ventura RA, Martin-Subero JI, Jones M, McParland J, Gesk S, Mason DY, et al. FISH analysis for the detection of lymphoma-associated chromosomal abnormalities in routine paraffin-embedded tissue. J Mol Diagn. 2006; $8: 141-51$. 